
(1)

\title{
A vivência de pessoas com estomia intestinal no grupo de apoio em um Hospital Universitário
}

\author{
Graciete S. Marques, ${ }^{1,2 *}$ Dayse C. Nascimento, ${ }^{2}$ Fernanda R. Rodrigues, ${ }^{3}$ Clara M. F. Lima ${ }_{1}^{4}$ Daniele F. Jesus ${ }^{4}$
}

\section{Resumo}

Trata-se de uma pesquisa descritiva com abordagem qualitativa. O objetivo deste estudo foi descrever os motivos que levam os estomizados a participarem do grupo de apoio e analisar suas repercussões. A população foi composta por pessoas com estomia intestinal que tiveram participação, no mínimo, de três encontros no grupo. A coleta de dados ocorreu entre abril e julho de 2015, a partir de entrevista semiestruturada com questões abertas referentes à temática. A pesquisa foi aprovada pelo Comitê de Ética e Pesquisa sob nํㅡㄹ CAAE: 42606015.3.0000.5259. Os resultados evidenciaram que a motivação em frequentar o grupo vincula-se à abordagem realizada pelos profissionais de saúde, e ainda, foram unânimes em destacar como viviam antes e depois do ingresso no grupo citado. Concluímos que as estratégias educacionais implementadas neste grupo de apoio ao estomizado refletem numa reabilitação positiva, oportunizando melhor aceitação pessoal e inclusão social, além de reforçar a assistência multidisciplinar deste hospital.

Descritores: Estomia. Promoção de saúde. Enfermagem. Educadores em saúde.

\section{Abstract \\ The experience of people with ostomy in the su- pport group in a University Hospital}

This is a descriptive research with a qualitative approach. The aim of this study was to describe the reasons why the ostomy participate in the support group and analyze its impact. The population consisted of people with ostomy who have participated at least three meetings in the group. Data collection took place between April and July 2015, from semi-structured interviews with open questions about the topic. The Research Ethics Committee approved the study under the number CAAE: 42606015.3.0000.5259. The results showed that motivation in attending the group is linked to under the approach made by health professionals, and also were unanimous in highlighting how they lived before and after the admission in that group. We conclude that educational strategies implemented in this support group to the ostomy reflect a positive rehabilitation, providing opportunities for better personal acceptance and social inclusion, and strengthen the multidisciplinary care of this hospital.

Keywords: Ostomy. Health promotion. Nursing. Health educators.
1. Seção Cirurgia Plástica. Hospital Universitário Pedro Ernesto. Rio de Janeiro, Brasil.

2. Comissão de Curativos do Hospital Universitário Pedro Ernesto. Rio de Janeiro, Brasil.

3. Distribuidora cirúrgica Ipanema Privada. Rio de Janeiro. Brasil.

4. Estratégia da saúde da família (ESF). Secretaria Municipal de Saúde do Rio de janeiro. Rio de Janeiro, RJ, Brasil.

*Endereço para correspondência:

Coordenação de Enfermagem, HUPE

Boulevard Vinte e Oito de Setembro, 77, 3o andar

Rio de Janeiro, RJ. CEP: 20551-030.

E-mail: graciesmar@gmail.com

Revista HUPE, Rio de Janeiro, 2016;15(2):113-121

doi: 10.12957/rhupe.2016.28235

Recebido em 01/07/2016. Aprovado em 18/10/2016.

\section{Resumen}

La experiencia de las personas con ostomía intestinal en el grupo de apoyo en un Hospital Universitario

Se trata de una investigación descriptiva con enfoque cualitativo. El objetivo de este estudio fue describir las razones que llevan a los ostomízados a participar en el grupo de apoyo y a analizar su impacto. La población estuvo constituida por personas con ostomía intestinal que hubiesen participado al menos de tres reuniones en el grupo. La recolección de datos se llevó a cabo entre abril y julio de 2015, a partir de entrevistas semiestructuradas con preguntas abiertas sobre el tema. El estudio fue aprobado por el Comité Ética e Investigación con el número CAAE: 42606015.3.0000.5259. Llegamos a la conclusión de que las estrategias educativas implementadas en este grupo de apoyo al de ostomía reflejan una rehabilitación positiva , brindando oportunidades para una mejor aceptación personal e inclusión social, y fortaleciendo la atención multidisciplinaria de este hospital.

Palabras clave: Ostomía; Promoción de la salud; Enfermería; Educadores de salud. 


\section{Artigo original}

\section{Introdução}

A pessoa portadora de estomia intestinal possui um orifício no abdome confeccionado cirurgicamente a partir de um segmento intestinal o qual é denominado estoma. Esse tipo de estoma tem o objetivo de eliminar drenagem de efluentes intestinais, assim, consequentemente, oferecer recuperação e maiores chances de sobrevida ao estomizado..$^{1-2}$

A indicação cirúrgica de um estoma intestinal está relacionada a várias causas, como por exemplo, o câncer de cólon e reto, as doenças inflamatórias, as anomalias congênitas e a diversidade de lesões acometidas aos traumas abdominais. ${ }^{1}$

A terminologia atualmente utilizada é de "estoma, estomia", porém ainda se percebe o emprego de "ostoma, ostomia", ambas referem-se ao mesmo problema.

O estudo utilizará o termo "estoma, estomia" por ser adotado pela Associação Brasileira de Estomaterapia (SOBEST), voltado para o cuidado com pessoas com vários problemas, dentre os quais as estomias, nos aspectos preventivos, terapêuticos e de reabilitação. ${ }^{3}$

A indicação cirúrgica de um estoma intestinal está relacionada a várias causas, como por exemplo, o câncer de cólon e reto, as doenças inflamatórias, as anomalias congênitas e a diversidade de lesões acometidas aos traumas abdominais, no qual faz parte da área de atuação exclusiva do enfermeiro, reconhecida como uma especialidade latu sensu no Brasil a partir de 1990. Nesse contexto, a tal especialidade oferece competências e atribuições dentre as quais destacamos as ações para o estímulo no retorno do estomizado à participação social assim como em associações ou grupos de autoajuda. ${ }^{3}$

Cabe destacar que das pessoas estomizadas, o câncer do cólon e reto é a doença de base que mais prevalece na construção cirúrgica para estomia, à medida que as taxas da doença são crescentes no Brasil.1.,4]

A presença de pólipos intestinais, consideradas lesões benignas, são responsáveis pelo surgimento de grande parte desses tumores. Nesses casos, a estimativa de novos casos do Instituo Nacional do Câncer (INCA) em 2014 foi de 32.600 , sendo 15.070 homens e 17.530 mulheres. ${ }^{4}$

Estudos do INCA indicam que o câncer de cólon e reto é o terceiro mais incidente no país e ocupa o segundo lugar na região Sudeste. Para esse tipo de câncer, os fatores de risco estão diretamente ligados a alimentação inadequada, ao envelhecimento, histórico da doença em parentes próximos e descontrole do peso. ${ }^{4}$
A doença de Crohn (DC) e a retocolite ulcerativa idiopática (RCUI) são classificadas como doenças inflamatórias intestinais. A DC atinge qualquer segmento do tratogastrointestinal, porém é mais frequente em partes do íleo terminal e cólon. São lesões ulcerativas aftosas ou profundas e erosões. A RCUI acomete somente o cólon e são úlceras rasas somente na mucosa., 5,

É importante ressaltar, que as doenças inflamatórias podem resultar na confecção de um estoma, mas suas características são diferentes no que se refere ao tratamento. Na DC, as complicações mais comuns que resultam na estomia, são as perfurações bloqueadas ou em peritônio livre, as deiscências de anastomose e sepse anorretoperineal persistente ou não., ${ }^{5,6}$

Com relação aos traumas abdominais como causa de indicação do estoma, há uma diversidade de tipos de lesões quanto à natureza e gravidade que podem ser variadas, destacam-se a violência urbana, acidentes automobilísticos, e, até mesmo, uma grave constipação intestinal. Tais situações acometem qualquer pessoa em qualquer idade de forma repentina, assim impondo uma nova realidade repleta de restrições com mudanças bruscas do hábito de vida. Todas essas situações, aliadas a muitas outras, têm provocado um número crescente de pessoas que a cada dia se tornam estomizadas?

No Brasil, com relação ao quantitativo de pessoas com estomia, estimava-se, em 2003, haver cerca de 50 mil, segundo dados provenientes da Associação Brasileira de Ostomizados (ABRASO). ${ }^{7}$

Não há dados atualizados para esse quantitativo, o que nos leva a uma estimativa atual maior, haja vista, a estimativa de incidência de câncer intestinal pelo INCA, das doenças inflamatórias e do aumento de violência social. ${ }^{4,7}$

Assim, de acordo com a etiologia e do grau de comprometimento da doença intestinal, o cirurgião indicará a confecção de estomias: ileostomia ou colostomia, designadas assim conforme a exteriorização do segmento intestinal, de caráter provisório ou definitivo.

Independentemente do caráter temporário ou definitivo, o estomizado passará por sérias mudanças na fisiologia gastrintestinal, em sua autoestima, imagem corporal, vida laborativa, familiar, sexualidade e social., ${ }^{8,9}$

O Decreto n. 9.296 , de 2 de dezembro de 2004, classifica a estomia como deficiência física, sendo assim, a pessoa estomizada é reconhecida pelo Sistema Único de Saúde (SUS) como deficiente físico. ${ }^{10}$

A literatura confirma as mudanças físicas radicais 
na vida do estomizado: a forma com que realizava as eliminações intestinais via anal agora é modificada, passando a conviver e se adaptar com a eliminação através do estoma na parede abdominal. ${ }^{8 \cdot 9,11-13}$

O estomizado necessita adquirir novos conhecimentos que os possibilitem uma rotina de vida menos traumática para retomar às suas atividades diárias. Nesse contexto, os profissionais de saúde, atuantes como equipe multidisciplinar, são fundamentais na reabilitação deste estomizado. ${ }^{8-9,11-16}$

No ambiente hospitalar, busca-se na fase pré-operatória, estabelecer um canal efetivo de comunicação entre o paciente e equipe multidisciplinar, além disso, procura-se incluir também a família. A presença da família é justificada pelo desconhecimento sobre a confecção cirúrgica do estoma e suas implicações que possam repercutir no paciente. ${ }^{15}$

Sendo assim, faz-se necessário que a equipe de saúde implemente uma assistência planejada, individualizada e sistematizada, em prol de colaborar e ajudar ao estomizado como lidar com medos, ansiedades, expectativas e ativando os mecanismos de enfrentamento. ${ }^{15}$

Sendo assim, a família é um vínculo primordial entre o estomizado em colaboração com as metas de reabilitação da equipe multidisciplinar.

Considera-se que a reabilitação seja um processo longo para ser alcançado, no qual contempla que envolve múltiplas dimensões. Ela vai além da recuperação de funções perdidas ou alteradas, como, por exemplo, os aspectos físicos, psicológicos, sociais, espirituais, econômicos e políticos. Toda reabilitação deve visar a adaptação dos sujeitos a sua nova condição de vida, preparando-os, acompanhados de sua família, para superação de todas as adversidades que poderão ocorrer. ${ }^{14-16}$

Nesse sentido, a existência, no Hospital Universitário Pedro Ernesto (HUPE), de um grupo multidisciplinar de apoio ao estomizado, denominado "À flor da pele e, com muito carinho", vem atuando desde 2010, a partir da iniciativa de enfermeiras da área cirúrgica. Tal grupo atua na reabilitação do estomizado com os objetivos de propiciar integração com outros estomizados do hospital, contribuir para o uso construtivo da ansiedade associada à satisfação de superar tarefas e desafios sociais, estabelecer troca de experiências entre o grupo e promover o sentimento de autoconfiança para o auto cuidado. ${ }^{16}$

Prosseguindo nesse aspecto, a equipe multidisciplinar deve iniciar o processo de reabilitação.É fundamental que o profissional de saúde oriente o paciente desde a fase pré-operatória, compreendida como arcabouço na reabilitação satisfatória inclusive com o estímulo para participação em grupos de apoio. ${ }^{17-18}$

Passado o período de 5 anos da existência desse grupo "À flor da pele e, com muito carinho", algumas perguntas nos despertaram o interesse com relação, quais seriam as repercussões na vida dos estomizados deste hospital universitário?

\section{Considerações sobre a assistência multidisciplinar ao estomizado}

O sofrimento da pessoa com estomia intestinal reforça a necessidade de uma orientação multidisciplinar, tendo este um cuidado integrado e diferenciado, ajustado às suas necessidades básicas, respeitado como indivíduo único, provido de uma história, de valores, mantendo seu papel na sociedade, além da valorização pessoal. $2,8,12,17$

Em nossa prática, consideramos que os pacientes com uma estomia temporária demonstram temores e preocupações semelhantes àqueles com um estoma permanente ou definitivo. Infelizmente por vezes, existe a possibilidade de a condição temporária tornar-se permanente para o paciente, em consequência de uma evolução clínica desfavorável que impedirá a reconstrução do trânsito intestinal.

Destacamos a fase de pós-operatório mediato: assim que o paciente tenha condições de aprendizado, o enfermeiro deve fornecer orientações educativas dos cuidados com a pele periestoma e troca de bolsas coletoras. Nesse momento, torna-se importante franquear e estimular a presença da família, enfim oportunizar uma rede apoio,

O apoio familiar desempenha importante cuidado holístico, assim como outros tipos de rede de apoio para este cuidado também podem ser ofertados além dos laços e vínculos de parentesco, tais como amizades, membros de congregações religiosas e grupos de apoio. ${ }^{18,19}$

Na fase tardia, a do pós-operatório, precisamente no acompanhamento ambulatorial, deve-se continuar a estimular ao retorno da pessoa estomizada à participação social, enfatizar a importância da participação na Associação de Estomizados ou grupos de autoajuda. . $^{15-19}$

Nesse contexto, destacamos em nossa prática no HUPE, algumas atuações dos referidos profissionais que compõem esse grupo de apoio.

O enfermeiro atua com sua equipe de enfermagem em todo segmento hospitalar, atuando nos cuidados e orientações educativas, são algumas ações do enfermeiro: no pré-operatório a demarcação abdominal do local 


\section{Artigo original}

onde será confeccionado o estoma e no pós operatório realiza e orienta para as trocas de bolsas coletoras e cuidados com a pele, favorecendo o autocuidado.

A equipe médica deste hospital do serviço de coloproctologia permanece também acompanhando o paciente estomizado pelo serviço no seguimento ambulatorial, local no qual são direcionadas as metas e feitos os encaminhamentos para outras especialidades conforme especificidades determinadas pela doença de base. Neste hospital universitário, o cirurgião coloproctológico acompanha e planeja, quando possível, a reconstrução do trânsito intestinal dos pacientes do serviço. Nas situações de ocorrências de complicações com a estomia ou deficit de orientações no autocuidado, os encaminhamentos são feitos para a enfermeira da unidade de internação de cirurgia geral ou para a sala da comissão de curativos.

O nutricionista responsável pela unidade de cirurgia geral do HUPE tem participação valiosa em incentivar o estomizado quanto a aceitação da terapia nutricional necessária para cada tipo de estomia, e, no seguimento ambulatorial, faz acompanhamento principalmente na avaliação do peso ideal e valor nutricional de uma alimentação saudável.

$\mathrm{O}$ assistente social destaca-se no uso de suas atribuições com orientações ao estomizado e família amparada na Resolução Normativa $n^{\circ}$. 325, de 18 de abril de 2013, que dispõe sobre o Rol de Procedimentos e Eventos em Saúde no âmbito da Saúde Suplementar, regulamentação, dentre outros aspectos, quanto ao fornecimento de bolsas de coletoras, de que trata o artigo 10-B da Lei $n^{\circ} 9.656$, de $1988 .{ }^{20}$

Por ocasião da alta hospitalar, todo estomizado deve ser encaminhado ao Programa de Atenção À Pessoa Ostomizada, do município de sua residência, subsidiado pelo SUS. No programa, é previsto um atendimento por um profissional especializado, que deve incluir treinamento e desenvolvimento de habilidades na troca da bolsa coletora. Esse programa também deve conter estratégias educacionais que visem à interrelação com outros estomizados por meio de reuniões, além de direcionar ao polo distribuidor regional, conforme sua área de domicílio, para receber gratuitamente os equipamentos coletores e adjuvantes de proteção e segurança. $^{20}$

Dessa forma, os estomizados são considerados legalmente portadores de deficiência, pois se entende que houve uma doença prévia que deixou uma deficiência no sistema excretor e produz limitações em várias esferas da vida, tanto social quanto pessoal. ${ }^{20}$
É importante destacar o relevante papel em defesa da cidadania da pessoa com estomia exercido pela ABRASO (Associação Brasileira de Ostomizados), uma associação civil sem fins lucrativos fundada na década de 80, de Utilidade Pública Federal, Estadual e Municipal, voltada para a defesa da cidadania da pessoa com estomia. É filiada à Associação Internacional de Ostomizados e tem como missão, dentre outros propósitos, a reunião das associações em âmbito nacional na defesa da cidadania dos estomizados, exigir do serviço público o fornecimento de bolsas coletoras gratuitas, promover a união dos estomizados brasileiros e fazer ser reconhecida a Declaração de Direitos Universais do Ostomizado. ${ }^{21}$

A declaração de direitos universais ao estomizado apresenta as necessidades especiais desse grupo específico e os cuidados que eles requerem. Tais diretrizes estão apontadas descritas na Portaria n 400, de 16 de novembro de 2009, que normatiza o atendimento à pessoa estomizada no SUS. O estomizado possui, entre outros direitos, o de receber aconselhamento pré-operatório para assegurar pleno conhecimento dos benefícios da cirurgia e dos fatos essenciais sobre viver com um estoma, assegurar localização correta com consideração integral e adequada ao conforto do paciente, ter apoio médico e profissional experiente, assim como o de receber cuidados de enfermagem especializada em estomas nos períodos pré e pós-operatório, tanto no hospital como na sua comunidade. ${ }^{21}$

\section{Sobre a atuação de grupos de apoio para o estomizado}

Deve-se entender que, em um grupo, todos os integrantes estão unidos para o alcance de um objetivo comum. Nesse contexto, trata-se de um grupo operativo terapêutico de apoio, cujo principal objetivo é ajudar seus membros a enfrentar o estresse da vida. Ali são oferecidos apoio emocional e informações educativas para o aumento das capacidades de seus membros, para o enfrentamento e a solução dos problemas, reforçando o sistema de apoio entre os pacientes..$^{22,23}$

Os componentes do grupo se identificam por semelhantes com as mesmas características e se ajudam reciprocamente, sem interesse financeiro, com princípios como: compartilhamento de experiências; educação e aprendizagem; autoadministração; aceitação de sua própria responsabilidade; objetivo único; voluntariado; desejo de mudança de vida e anonimato e respeito por todos do grupo. ${ }^{22-23}$

Os grupos de apoio permitem o encontro de pessoas 
com problemas semelhantes, o que facilita a troca de vivências e auxiliam as pessoas a encontrarem uma nova forma de conviver com o estoma. ${ }^{22-24}$

\section{Metodologia}

Trata-se de um estudo descritivo, exploratório com abordagem qualitativa, que possibilitou trabalhar com o universo dos significados, motivos, aspirações, crenças, valores e atitudes, correspondentes às relações dos processos e dos fenômenos, a fim de proporcionar o aprimoramento de ideias ou descoberta de intuições. ${ }^{25-26}$

Os objetivos foram descrever os motivos que levam os estomizados a participarem do grupo de apoio multidisciplinar nessa instituição e analisar suas repercussões na vida dos estomizados.

O cenário da pesquisa foi o grupo de apoio multidisciplinar ao estomizado do Hospital Universitário Pedro Ernesto, cujos participantes são pessoas com estomia intestinal. O grupo de apoio é vinculado às enfermarias de cirurgia geral feminina e masculina, no qual o serviço de coloproctologia está integrado. Surgiu em 2010, como resultado da iniciativa de duas enfermeiras estomaterapeutas. Desde então, vêm ocorrendo encontros trimestrais, com reuniões temáticas, workshops, palestras e discussões com os profissionais de saúde, os estomizados e seus familiares. Os contatos para as reuniões são realizados via telefone, cartazes na instituição e rede social. Desde seu início, em julho de 2010, a julho de 2015, ocorreram 23 encontros, tendo como frequência em média de 17 estomizados e de 9 familiares. Os encontros possuem demanda voluntária, tendo como justificativa o convite, e não de uma consulta obrigatória.

Como critério de inclusão, optou-se por convidar os estomizados que tenham frequentado pelo menos três encontros, assim conseguido a amostra composta por 15 participantes.

Os dados foram coletados no período de abril a julho de 2015, após aprovação do Comitê de Ética em Pesquisa do Hospital Universitário Pedro Ernesto, registrado na Plataforma Brasil sob $\mathrm{n}^{\circ}$ CAAE: 42606015.3.0000.5259, em março de 2015. Todos os participantes receberam informações a respeito do objeto investigado e assinaram termo de consentimento livre e esclarecido, formalizando sua anuência em integrar a pesquisa, conforme determinada a Resolução 466/2012.

A coleta de dados ocorreu a partir de uma entrevista estruturada, pré-agendada e após o aceite dos mesmos com roteiro contendo a caracterização dos sujeitos seguida de uma entrevista estruturada com questões abertas referentes à temática: O que motivou você a procurar o grupo de apoio dessa instituição? Sua participação no grupo de apoio interferiu em sua vida? Como? Quais são seus sentimentos antes e depois de participar do grupo de apoio?

Após a coleta de dados, as entrevistas respondidas foram digitadas no programa MS Word 2003, posteriormente codificadas e reunidas. Prosseguiu-se utilizando a análise temática de Minayo, a qual consiste no agrupamento de temas sobre o objeto investigado no intuito de estabelecer maiores relações e realizar possíveis inferências a partir do quadro teórico. ${ }^{26}$

\section{Resultados e discussão}

Dos 15 entrevistados, 10 (67\%) são homens e 5(33\%) são mulheres, 10 (67\%) possuem entre 21 a 59 anos, 8 (53\%) são casados, 6 (40\%) são amparados pelo benefício do INSS- Previdência Social como aposentados, 5 (33\%) com licença médica, 3 (20\% ) são ativos no mercado de trabalho como autônomos e 1 (7\%) é estudante. Quanto ao grau de escolaridade, 6 (40\%) possuem o $2^{\circ}$ grau completo com 40\%, 4 (27\%) que possuem ensino superior completo, nenhum analfabeto. Com relação ao tempo com o estoma, 8 (.53\%) estão estomizados de 9 meses a 3 anos, 6 (40\%) estão de 4 a 6 anos e 1 (7\%) é estomizado há 9 anos.

O câncer de cólon e reto foi o responsável pela confecção do estoma em 12 (80\%) pacientes, a doença inflamatória intestinal com retocolite em 2 (13\%) e houve 1 caso de trauma cirúrgico após apendicite, que representa 7\%.

Quanto ao caráter definitivo ou temporário da estomia, detectou-se em 6 (40\%) pessoas como condição definitiva, 5 (33\%) responderam sendo temporário e 4 (27\%) estomizados disseram desconhecer essa informação.

Quanto à participação nas reuniões e encontros do o grupo de apoio, 6 (40\%) estiveram entre 3 a 5 encontros, 5 (33\%) estiveram em mais de 5 encontros e 4 (27 $\%)$ disseram nunca terem faltado.

\section{Motivações para participar do grupo de apoio: convite especial, aprendizado e troca de experiências}

A palavra "motivação" denota "ato ou efeito de motivar", causa, razão ou estímulo que impulsionam algo ou que o determinam. Foi evidenciado a forma como o "convite" é utilizado pela equipe multidisciplinar, assim denota ser um aspecto facilitador, pois a demanda deve ser sempre espontânea. ${ }^{27}$ 


\section{Artigo original}

Assim, ajudar o estomizado a conviver com o estoma é, dentre outras ações, uma participação importante para o enfermeiro no processo de reabilitação, desenvolver seu autocuidado e ajudá-lo a superar a autorrejeição que, em muitos casos, impossibilita-o na convivência social. $2,8,9,14$

Vale citar a trajetória do Grupo de Apoio à Pessoa Ostomizada (GAO) do Hospital Universitário da Universidade Federal de Santa Catarina, criado em 1985, o qual foca nas diversas parcerias institucionais e política, tendo como fundamento projetar ações em saúde com troca de vivência e saberes baseadas nas necessidades dos estomizados a qual norteia a prática inteirando com a realidade. ${ }^{28}$

As motivações que levaram o estomizado a procurar o grupo de apoio foram expressas em 06 (40\%) entrevistas, nas quais se destacou o comunicado ou solicitação para participarem por meio de uma solicitação, sob a forma de convite.

A palavra "convite", além do significado do "ato de convidar, pedido de presença" é percebida como incentivo. ${ }^{27}$ Destacamos uma das falas a seguir:

"[...] não aceitava a situação, foi após o convite da assistente social" (E8).

A motivação também é configurada na vontade de adquirir aprendizado, descobrir por meio da razão ou da experiência e da capacidade para raciocinar aquilo que se aprendeu sobre um assunto. Pode-se exemplificar esse sentimento nas seguintes falas:

"[...] Aprender a ter autonomia, usando a bolsa" (E14).

"Necessidade de aprender" (E10).

"Necessidade de aprender para melhorar a vida" (E11). "Vontade de aprender" (E15).

"Esclarecimentos a respeito do problema, como viver com a estomia" (EO7).

Nesse sentido, a equipe multidisciplinar atua como promovendo o restabelecimento de saúde da pessoa estomizada por meio da implementação de práticas educativas e assistenciais que valorizem o ato de cuidar. ${ }^{15,18,29}$

Ainda neste contexto, percebe-se a vontade de convivência com outras pessoas estomizadas, como forma de adquirirem conhecimentos por meio de trocas de experiências nos problemas comuns. Cada um enfrenta as adversidades com um olhar diferenciado, e, no momento em que essas experiências são trocadas, os elos de confiança se fortalecem e motivam uns aos outros a enfrentarem novos desafios. A falta de conhecimento à nova condição do estomizado gera ansiedade tanto para o próprio paciente quanto para seus familiares, causando insegurança, o que pode levá-los a sentimentos negativos. Exemplificamos esses sentimentos nas falas a seguir:

"Conhecer pessoas que vivem com a bolsa" (E15).

"Fazer amizade, conhecer pessoas com o mesmo problema" (E13).

"A proposta da troca de experiências" (E09).

"Para não ficar abandonada em casa" (E03).

A importância do estomizado em adquirir conhecimento pela convivência com o grupo de apoio tem registro na literatura. ${ }^{16,19}$ Os registros destacam que ele passa a ser sujeito ativo do processo, por meio das trocas de experiências com o grupo. ${ }^{18-19,24,28}$

Consideramos que no grupo de apoio ao estomizado a pessoa se torna mais segura e fica menos ansiosa. A família facilita a aquisição de conhecimentos, visto que a rede de apoio oportuniza a inclusão dos familiares. ${ }^{15}$

\section{As repercussões como esperança de melhora ao estomizado}

Foi unânime a percepção de que a participação desse grupo de apoio interferiu e interfere positivamente em suas vidas como sendo também uma condição para o ganho de qualidade de vida. Os relatos são explicitados nas falas a seguir:

\section{[...]" Melhorar qualidade de vida, esperança de melho- $\mathrm{ra}^{\prime \prime}(\mathrm{E05})$. \\ "Melhorar a vida" (E 11).}

Segundo a Organização Mundial da Saúde (OMS) pode-se definir qualidade de vida como a percepção do indivíduo, de sua posição na vida, no contexto da cultura e sistema de valores nos quais ele vive e em relação aos seus objetivos, expectativas, padrões e preocupações. A qualidade de vida relacionada com saúde e estado subjetivo de saúde são conceitos afins, centrados na avaliação subjetiva do paciente, mas necessariamente ligados ao impacto do estado de saúde sobre a capacidade do indivíduo de viver de forma plena. ${ }^{11}$

Estudar a qualidade de vida de pacientes estomizados se faz necessário pelo fato de que aspectos da qualidade de vida parecem estar comprometidos nesses pacientes pelas repercussões que tal cirurgia traz para sua vida pessoal, emocional e social. Esses fatores são importantes para o cuidado de enfermagem na integralidade a pessoa com estomia intestinal. ${ }^{11}$

Ao indagar os participantes do estudo quanto às repercussões do grupo de apoio em suas vidas, pode-se identificar nas falas explícitas a melhora do estado geral 
e na imagem corporal a autoestima:

[...] "interfere na autoestima" (E04)

"Melhorou a qualidade. Melhorou muito a parte psicológica" (EO5).

"Fortalecer essa trajetória diferenciada, a suportar" (E10).

"Fiquei mais alegre" (E12).

"[...]a se cuidar... teve mais calma, melhorou a vaidade" (E14).

Mesmo quando a confecção do estoma é a única saída para resolução de problemas de saúde, esbarra-se na dificuldade que os indivíduos têm para se adaptarem a essa nova condição. Quando assume a atitude de não se entregar e decide fazer o que está ao seu alcance para sua melhor reabilitação, o estomizado busca apoio familiar ou em algum tipo rede de apoio para enfrentar a doença, e essa postura tende a aumentar seu sentimento de confiança e a apresentar melhor adaptação ao tratamento, o que demonstra enfrentamento positivo da doença.

Essa adaptação depende de inúmeros fatores que englobam, além de características pessoais, aspectos emocionais, culturais e experiências anteriormente vividas. O contexto da doença e da proposta terapêutica imposta também podem provocar estresse, fazendo com que o indivíduo lance mão da estratégia de "coping". 8

O termo "coping" não tem tradução equivalente para o português, porém pode ser entendido como uma tentativa de superar o que lhe está causando estresse. Desse modo, desenvolvem-se estratégias de enfrentamento com objetivo de um alcançar controle pessoal frente a uma situação de estresse. Essa estratégia pode ser aprendida, usada e adaptada conforme o repertório individual e as experiências vividas e pode ser focada no problema ou na emoção. ${ }^{8}$

A confecção de um estoma é um procedimento invasivo que altera a fisiologia intestinal e a imagem corporal do indivíduo. Esta alteração pode resultar em uma imagem distorcida e na diminuição da autoestima, sendo necessário, além de um suporte dado em relação aos cuidados físicos e ensino para o autocuidado, um suporte psicológico ligado ao ser emocional e a sua capacidade de enfrentamento. ${ }^{30}$

Diante disso, destaca-se que, ao lidarmos com o paciente estomizado, o primeiro passo a ser considerado é a questão da mutilação sofrida, visto que esta levará a alterações em sua imagem corporal. ${ }^{12-13,29}$

Percebe-se que os estomizados identificam a vivência no grupo de apoio, o fato de receberem palestras sobre a importância na reeducação alimentar, visando ao cultivo de novos hábitos alimentares mais saudáveis como uma interferência positiva. Outras interferências foram citadas, como por exemplo, valorizar atividades de lazer, de casa ou do trabalho, assim como também relativas aos cuidados higiênicos com o estoma e a troca de bolsas coletoras. Tais falas reforçam a integração da equipe multidisciplinar do grupo de apoio na reabilitação do estomizado.

Essas situações são exemplificados nas falas a seguir:

[...] "reeducação alimentar" (E 01).

"Orientação, esclarecimento" (E 07).

"Cuidar da estomia" (E 08),

"Ajudou a saber como usar a cinta" (E 02).

Por meio do conhecimento surge o entendimento de que a estomia significa a oportunidade de continuar vivo, o que representa uma outra opção de vida. ${ }^{11-13,30}$

\section{Sentimentos dos estomizados vivenciados antes e após o ingresso no grupo de apoio}

Antes de participar do grupo de apoio, os estomizados informam:

[...] "Ignorância." (E01)

[...] "ansiosa pois desconhecia como era ter a bolsa..." (E02)

[...] "inseguro antes" (E05)

[...] "Cabisbaixo, depressivo" (04)

[...] "um pouco isolado" (E03)

[...] "Deprimida, cabisbaixa, pensando em desistir da vida" (E08)

Tais falas evidenciam situações como o medo da discriminação, as limitações ocasionadas pela deficiência física, o despertar de sentimentos de piedade e aversão no coletivo social contribuem para seu isolamento. ${ }^{8}$

Os estudos confirmam que a inclusão do estomizado em seu meio social é permeada por inúmeras dificuldades, pois há muito receio em se enfrentar locais públicos, emergindo sentimento de tristeza, desânimo e isolamento social. ${ }^{12-13,29-30}$

No entanto, a participação do estomizado no grupo de apoio trouxe influências positivas para sua vida, sendo destacadas nas falas de conotações positivas, tais como:

[...]"Autoestima elevada e alegre" (E 04)

[...]"Mais seguro, mais determinado" (E05)

[...]" Melhorou o autocuidado" (E12)

Confirma-se, portanto, que a vivência em rede de apoios, como grupo de apoio, ajuda ou terapêutico incentivam os estomizados a se sentirem mais seguros 


\section{Artigo original}

e alegres. ${ }^{11,18-19}$

Verificou-se, neste estudo, que a maioria dos estomizados não retorna ao trabalho, pois foram amparados pelo benefício da aposentadoria devido à doença de base. Porém, vale refletir quando a aposentadoria ocorre principalmente em sujeitos mais jovens, visto que contribui para ociosidade, isolamento social e sentimentos de inutilidade. ${ }^{11,14}$

Diante desses sentimentos de conotações negativas, pode-se enfatizar a importância da assistência ao estomizado e sua família na abordagem interdisciplinar e especializada com vistas à recuperação, física e reabilitação.

\section{Conclusão}

O estudo favoreceu reflexões sobre a troca de saberes e práticas na educação em saúde sob a forma de grupo de apoio e possibilitou uma visão acerca da vivência dos estomizados no HUPE.

Conclui-se que este grupo de apoio utiliza uma dinâmica facilitadora na qual reconhece que, à medida que o estomizado sente-se acolhido e ouvido nessa equipe multidisciplinar, ele consegue interpretar melhor não apenas seus questionamentos como também permite que sejam úteis, compartilhando suas experiências com semelhantes.

As estratégias educacionais implementadas por esses profissionais neste grupo de apoio ao estomizado oportunizam o desvendamento de vários desafios trazendo à tona novos olhares à sua condição física, possibilitando vivência com maior autonomia e participação social.

A reinserção social do estomizado ocorre na capacidade individual em enfrentar e superar o impacto da doença no seu estilo de vida, atreladas ao convívio com essa rede de apoio de pessoas com problemas semelhantes. Assim destacamos o fato de se sentirem úteis, bem como sua capacidade de exercer novamente suas atividades rotineiras, o que os leva se sentirem menos solitários.

Neste grupo de apoio os referidos profissionais estão integrados na assistência à saúde e, na condição de equipe multidisciplinar, funcionam como estruturas dinâmicas amadurecidas, as quais refletem na reabilitação positiva do estomizado em tratamento neste hospital universitário.

Finalmente, conclui-se que o tema não se esgota para o estomizado, reforça a necessidade da manutenção deste tipo de estratégia com grupos apoio/ terapêuticos nas diversas áreas da saúde com foco na reabilitação do paciente.

\section{Referências}

1. Luz MHBA, Andrade DS, Amaral HO, et al Caracterização dos pacientes submetidos a estomas intestinais em um Hospital de Teresina-PI. Texto Contexto Enferm, Florianópolis, 2009 JanMar; 18(1):140-6.

2. Mirand SM, Nascimento CMFS, Luz MHBA, et al . Viver com Estomia: Contribuições para a Assistência de Enfermagem. Revista Estima . 2014;12(3). Disponível em: <http://www.revistaestima.com.br/index.php/estima/article/view/94> Acesso em 10 de out de 2015)

3. Yamada BFA, Ferrola EC, Azevedo GR, et al. Competências do enfermeiro estomaterapeuta (ET) ou enfermeiro pós-graduado em estomaterapia (PGET). Rev. Estima. 2008:6(1):33-43.

4. Instituto Nacional de Câncer. Coordenação de Prevenção e Vigilância do Câncer Ministério da Saúde. Estimativa 2014: incidência de câncer no Brasil. Rio de Janeiro: INCA, 2014. Disponível em:<http://www.inca.gov.br/estimativa/2014>. Acesso em: 18 set. 2014.

5. Cabral MG, Abby F. Diagnóstico das Doenças Inflamatórias intestinais. Revista do Hospital Universitário Pedro Ernesto, UERJ, Rio de Janeiro. 2012;11(4):17-21.

6. Cury DB, Moss AC. Doenças inflamatórias intestinais: Retocolite e Doença de Crohn, RJ. Ed. Rubio; 2011.187-196.

7. Associação Brasileira de Ostomizados. Ostomias originadas por trauma. Rev. ABRASO. Rio de Janeiro.2007(8):12-14.

8. Coelho AR, Santos FS, Poggetto MTD. A estomia mudando a vida: Enfrentar para viver. Rev Min Enferm. 2013;17(2):258-67.

9. Santos VCG, Umbelina I. Assistência em estomaterapia: cuidando da pessoa com estomia. São Paulo: Atheneu, $2^{\mathrm{a}}$ ed; 2015. 624p.

10. Brasil. Decreto $n^{\circ} 5.296$, de 02 de dezembro de 2004. Estabelece normas gerais e critérios básicos para a promoção da acessibilidade das pessoas portadoras de deficiência ou com mobilidade reduzida, e dá outras providências. Diário Oficial da União, Brasília, DF, 3 de dezembro de 2004; Cap II, Art. $5^{\circ}$.

11. Flora AD, Gomes JS. Qualidade de vida de portadores de estomia intestinal: uma revisão narrativa. 2012. Dissertação (Conclusão de curso em Enfermagem) - Universidade Regional do Noroeste do Estado do Rio Grande do Sul. Departamento de ciências da vida. Curso de enfermagem IJUÍ, RS. 2012.

12. Mota MS, Gomes GC. Mudanças no processo de viver do paciente estomizado após a cirurgia. Rev enferm UFPE on line. Recife. 2013;7(esp):7074-81.

13. Nascimento CMS, Trindade GLBV, Luz MHBA, et al. Vivência do paciente estomizado: Uma contribuição para Assistência de Enfermagem. Texto Contexto Enferm, Florianópolis, 2011;20:557-64

14. Mauricio VC, Souza NVDO, Lisboa MTL. O enfermeiro e a sua participação no processo de reabilitação da pessoa com estoma, Esc Anna Nery (impr.)2013;17(3):416-22.

15. Lenza NFB, Sonobe HM, Buetto LS, et al. O ensino do autocuidado aos pacientes estomizados e seus familiares: Uma revisão integrativa. Rev Bras Promoç Saúde. 2013;26(1):139-145.

16. Dias CDG, Rodrigues FR, Marques GS, et al. Perfil do grupo de portadores de estomia intestinal de um hospital Universitário do Rio de Janeiro: "A flor da pele, e com muito carinho". In: Seminário Nacional de Pesquisa em Enfermagem - SENPE, 17. 2013, Rio Grande do Norte. Anais eletrônicos. Natal: Hotel Praia Mar; 2013. p.2177-8. Disponível em: www.abeneventos. 
Graciete S. Marques e cols. • A vivência de pessoas com estomia intestinal no grupo de apoio em um Hospital Universitário

com.br/anais_senpe/17senpe/pdf/1407po.pdf. Acesso em: 15 set. 2014.

17. Mendonça RS, Valadão M, Castro L, et al. A Importância da Consulta de Enfermagem em Pré-operatório de Ostomias Intestinais. Rev Brasileira de Cancerologia. 2007;53(4):431-435.

18. Silva AL, Shimizu HE. A relevância da Rede de Apoio ao estomizado. Rev Bras Enferm. 2007;60(3):307-11.

19. Rodrigues AS, Budó MLD, Simon BS, et al. As redes sociais de apoio no cuidado às pessoas com estomias: Revisão Bibliográfica. Saúde (Santa Maria),2013(39)(1):33-42.

20. Brasil. Portaria $n^{\circ} 400$, de 16 de novembro de 2009. Estabelece Diretrizes Nacionais Para Atenção à Saúde das Pessoas Ostomizadas no âmbito do Sistema Único de Saúde- SUS. Diário Oficial [da] República Federativa do Brasil, Brasília, DF, 16 nov. 2009. Seção 1, p. 41-42.

21. Associação Brasileira de Ostomizados. Declaração dos Direitos dos Ostomizados. Rio de Janeiro (RJ): ABRASO; 2003 [citado em 05 set 2014]. Disponível em: http// www.abraso.org. br/ declaração.htm.

22. Galvan GB. Equipes de saúde: o desafio da integração disciplinar. Rev. SBPH [online]. 2007;10(22):53-61 . Disponível em: http://pepsic.bvsalud.org/scielo. Acesso em: 2015 Out-20.

23. Spadini LS, Souza MCBM. Conceito de grupo na percepção de enfermeiros na área de saúde mental e psiquiatria. SMAD,
Rev. Eletrônica Saúde Mental Álcool Drog. (Ed. port.) [online]. 2011 [citado em 30 jun 2015];7(3):133-138. Disponível em:http://pepsic.bvsalud.org/scielo.php?script=sci_arttext\&pid=S1806-69762011000300004\&lng=pt\&nrm=iso

24. Barros EJL, Souza JL, Gomes GC. O grupo de apoio como tecnologia educativa: Instrumento para o autocuidado do indivíduo estomizado. Periódicos UEM. 2013. Disponível em: <http://www.periodicos.uem.br/ojs/index.php/CiencCuidSaude/article/viewFile/20662/pdf. Acesso em: 12 out 2015.

25. Gil AC. Como elaborar projeto de pesquisa. $5^{\mathrm{a} e d}$. São Paulo: Atlas, 2010.

26. Minayo MCS, Deslandes SF, Neto OC, et al. Ciência, Técnica e Arte: $O$ desafio da pesquisa social. In: Pesquisa social, teoria, método e criatividade, 23 ed. Petrópolis: Vozes; 2004. p.09-29.

27. Ferreira $A B H$. Dicionário Aurélio da língua portuguesa. 5 ed. Curitiba: Positivo; 2014. 2272p.

28. Martins ML, Silva RDM, Fangier A, et al. Trajetória do Grupo de Apoio à Pessoa Ostomizada: Projetando Ações em Saúde e Compartilhando Vivências e Saberes. Texto Contexto Enferm, Florianópolis, 2005;14(4):594-600.

29. Silva DF, Santos FHE. O desafio do autocuidado para pacientes oncológicos estomizados. Rev. Estima. 2014;12(2):28-34.

30. Cassero P, Aguiar JE. Percepções emocionais influenciadas por uma estomia. Rev, Saúde e Pesquisa. 2009;2(2):23-7. 